\title{
A origem do mal e o crepúsculo da razão na obra do Rei de Amarelo de Robert W. Chambers: teologia e literatura na cultura popular contemporânea.
}

\author{
Julio César Pasqualinato Rodrigues ${ }^{1}$
}

\section{RESUMO}

Nesse artigo irei abordar o tema da origem do mal a partir das referências apresentadas no gênero literário denominado "fantasia sombria" com foco na obra de Robert W. Chambers, o Rei de Amarelo. O objetivo do artigo é apresentar a hipótese de que as influências diretas do gênero remontam à experiência religiosa que se traduziu na filosofia gnóstica que ganhou notoriedade a partir do século 2 d.C. Por fim; o artigo fará alguns apontamentos sobre a influência desse gênero na literatura e cultura popular do mundo contemporâneo.

Palavras-chave: gnosticismo, fantasia sombria, literatura, mal, razão.

The Origin of Evil and The Twilight of Reason in the Work of Robert W. Chambers' Yellow King: Theology and Literature in Contemporary Popular Culture

\section{ABSTRACT}

The paper addresses the origin of evil theme from the references presented in the literary genre dark fantasy, focusing on the work of Robert W. Chambers, the King of Yellow. The article objective presents the hypothesis that the direct influences of the genre and the religious experience translated in the gnostic philosophy gained notoriety form the second century AD. Some notes are made about the influence of the dark fantasy genre in literature and popular culture of the contemporary world. Key Words: Gnosticism, dark fantasy, literature, evil, reason.

Doutorando em ciências da religião e professor da rede estadual de educação. 


\section{Introdução}

O rei de amarelo é uma obra de ficção e terror publicada por Robert Chambers ${ }^{2}$ em 1895, cujas influências ${ }^{3}$ remontam a Ambrose Bier$\mathrm{ce}^{4}$ em o conto do "Habitante de Carcosa" e as flores do mal de Charles Baudelaire. O livro é dividido em dez contos: o reparador de ilusões, a máscara, no pátio do dragão, o emblema amarelo, a demoiselle d'ys, o paraíso do profeta, a rua dos quatro ventos, a rua da primeira bomba, a rua de nossa senhora dos campos e Rue Barrée. Os temas abordados nos contos são o terror psicológico, o terror cósmico, revelações, sonhos e morte. Neste artigo, irei expor algumas evidências que apontam para uma intertextualidade entre a teologia gnóstica e a mitologia de terror cósmica do gênero em questão, mostrando suas semelhanças e distâncias em especial ao valor que as duas mitologias lidam com a importância da razão como ponto de transcendência primordial da espécie humana.

\section{Gnosticos e o caos primordial}

"Aquele que luta contra monstros, deve acautelar-se para não

Tornar-se também um monstro. Quando se olha muito tempo para um abismo, o abismo olha para você". Friedrich Nietzsche

2 Robert W. Chambers (Brooklyn, 26 de maio de 1865 - 16 de dezembro de 1933) foi um ilustrador e escritor de ficção estadunidense, mas conhecido por seu livro o Rei de amarelo, publicado em 1895. Chambers estudou na École des Beaux-Arts e na Académie Julian, em Paris. Antes de se tornar escritor, trabalhava como pintor e ilustrador, tendo ilustrações publicadas em revistas Life, Truth e Vogue. Fez grande sucesso com o livro de terror o Rei de amarelo, mas depois de alguns outros livros do mesmo gênero, abandonou a literatura fantástica para se dedicar a romances históricos.

3 Essa é uma edição comentada por Carlos Osi, portanto essa pesquisa feita sobre as influências da obra recorre a afirmações do comentador em questão publicadas no próprio livro do rei de amarelo.

4 Ambrose Gwinnett Bierce (1842-1913), foi um crítico satírico, escritor e jornalista estadunidense, particularmente conhecido pela obra o "Dicionário do diabo". Definia que "sozinho" era estar em má companhia. Bierce fez do cinismo, misturado com humor negro, sua marca registrada. Família, nação, raça humana: nada escapava de suas críticas. 


\subsection{Gnósticos}

De acordo com muitas lideranças religiosas, os gnósticos não passam de hereges e maculadores da palavra sagrada, e seus evangelhos, conhecimento literário e poesias, um conhecimento a ser ignorado. Nos manuais de filosofia, e mesmo nos cursos de grandes universidades brasileiras, os gnósticos são notas de rodapés de cursos de graduação, raramente levados a sério, visto que para muitos, o tema da religião é frequentemente visto como um tema marginal. Entretanto o gnosticismo é um marco importante na história do pensamento que criou diversas ramificações e, mesmo hoje, tendemos a acreditar, que influencia escolas de pensamento em variados setores do saber, tais como: o ceticismo, no campo da filosofia e a fantasia sombria na área da literatura. A palavra "gnóstico" pode ser interpretada de duas maneiras: 1) em um sentido amplo: como uma designação para os movimentos religiosos que ganharam notoriedade no segundo século e 2) em um sentido restrito e histórico, como nome de uma antiga seita cristã, cuja língua básica era o grego: os gnósticos.

Assim como a maioria dos movimentos religiosos, os gnósticos possuem uma narrativa fundamental, que serve de pressuposto para as reflexões de seus seguidores, que também lhes confere uma identidade. Neste artigo, não irei aprofundar a discussão sobre os documentos e a história dos gnósticos, meu interesse está exclusivamente na narrativa fundamental e na visão filosófica criada por eles. Para tal, vou usar como referência a pesquisa de Bentley Layton, publicada em seu livro: "As escrituras gnósticas". O mito gnóstico de criação é composto por quatro atos: 1. A emanação do universo espiritual; 2. criação do universo material; 3. Criação de Adão, Eva e seus filhos e 4. História subsequente da raça humana (LAYTON, 2002). Como descrito acima, iremos limitar nossa atenção ao mito fundante, e especificamente aquele que considero a base mais importante para a visão desenvolvida pelos gnósticos que é objeto de análise desse texto.

No segundo ato do mito: a criação do universo material, há uma afirmação, que faria qualquer cristão fundamentalista, "ficar de cabelo em pé". A de que "Deus" não é demiurgo de toda a criação. Acompanhemos a passagem do mito que faz essa afirmação: 
Depois de completada a emissão do universo espiritual, para que a continue para além do limite da existência espiritual, se introduz a atividade de "artificie" 5 ou "fabricante" do mundo; seu nome é Ialdabaõth. Essa parte do mito é evidentemente calcada no mito da criação, de Platão, que se encontra em Timeu. Ialdabaõth, o artesão, com a matéria faz o universo, copiando modelos fornecidos pelo universo espiritual. É uma estrutura elaborada de éons (reinos) materiais, i. é, planetas, estrelas e esferas celestes, povoados pelos filhos do artesão, que são chamados "governantes", "autoridades", "poderes", "demônios", “anjos", etc. (LAYTON, Bentley, 2002, p.16).

Essa narrativa apresenta uma interpretação teológica interessante, visto que Deus, não é o arquiteto do mundo material, e, por conseguinte não seria responsável pelo mal no mundo, o mal é resultado da criação material concebida por Ialdabaõth ${ }^{6}$, que, se tratando de uma entidade possessiva e arrogante, não estaria em boas mãos. Então, segundo os gnósticos, o artesão do mundo material é uma entidade que não trabalha em favor da humanidade, ou pouco se importa com ela. Em meditações metafisicas, uma das obras mais icônicas de René Descartes, há uma hipótese parecida; onde a humanidade, criada a partir da vontade de uma espécie de arquiteto, ressente tanto de sua criação que o arquiteto a aprisiona em barris de vinho, visando o entorpecimento da espécie, como uma estratégia de manter controle sobre ela (DESCARTES, 2011). Essa hipótese apresentada pelos gnósticos implica na ideia de que o mundo não tem solução, criado por uma entidade possessiva e arrogante, cabe somente ao ser humano, se entregar ao desespero, visto que ele está sozinho, não é amado, nem acompanhado, por entidades superiores e metafisicas. Assim o mundo seria como uma interminável peça de teatro, explicada muito bem na frase de Shakespeare: "a vida é uma história contada por um idiota, cheia de som e fúria, sem sentido algum." Importante esclarecer que para os gnósticos, Ialdabaõth não é uma entidade maligna, já que reconhece o bem e admira as criações perfeitas do mundo espiritual, mas possui uma moral ambígua, refletindo no mundo a própria ambiguidade. Como Ialdabaõth e seus

\footnotetext{
5 Artificie, demiurgo (grego demiurgos) é o termo metafórico que Platão usa para designar o criador do universo em seu relato mítico da criação do mundo intitulado Timeu.

6 O nome dessa entidade gnóstica provavelmente foi inspirado na entidade da entidade judaica de mesmo nome, e que exerce, na mitologia judaica a mesma função de artesão.
} 
companheiros governantes tentam controlar os negócios humanos, seu desejo de controlar e dominar resulta na pouca e quase inexistência da possibilidade humana de controlar ou mudar seu destino para além do roteiro imaginado pelo pai artesão. Desse conflito nasce a tragédia (segundo os gnósticos): o ser humano que questiona e luta para entender seu papel no mundo, encara a vida nos limites impostos por um criador autoritário e intolerante, que não permite sua autogestão.

Mas a pergunta que muitos se fazem: então, permitiria Deus que um idiota, cheio de som e fúria, continuasse como artesão do mundo material e por conseguinte, da realidade humana? A literatura gnóstica responde da seguinte forma:

Aos olhos dos gnósticos, o ato final do drama ainda está em progresso. Um salvador celestial foi enviado para "despertar" a humanidade gnóstica, para dar-lhe conhecimento (gnosis) de si mesma e de deus, para libertar as almas do destino e da escravidão material, e para ensiná-las como escapar à influência dos malévolos "governantes" (LAYTON, Bentley, 2002, p.17).

Essa passagem mostra o ponto de ruptura com a teologia criada pelos cristãos do quarto século ${ }^{7}$ : para os gnósticos, Jesus (o salvador celestial) é uma espécie de guia espiritual da humanidade, que ensina a sabedoria necessária para se libertar da realidade opressora e autoritária de Ialdabaõth, libertação que ocorre através do conhecimento. Saber que a realidade é construída por um idiota cheio de som e fúria é que permite ao indivíduo a salvação e transvaloração das leis morais impostas pelo artesão. Com esse arranjo teológico fica claro que Deus se importa com o plano material, a ponto de mandar seu filho como condutor do povo gnóstico para além dos limites da vida aprisionada pela caverna construída pelo criador da realidade material.

\subsection{O caos primordial}

Como explicado no tópico anterior, a teologia gnóstica oferece uma visão de mundo diferente daquela concebida pelos cristãos do primeiro século, e posteriormente no século 4 d.C., do cânon que fundou a igreja

Estamos nos referindo ao cristianismo canônico pós concilio de Nicéa em 325 d.C. 
católica apostólica romana. Para a teologia oficial da igreja católica, Deus é o demiurgo de toda a realidade, em suas dimensões espirituais e materiais, portanto não existe mal na criação, toda a criação é perfeita. O mal nessa interpretação do mito surgiu com o pecado original. A mulher, manipulada pela cobra, convence o homem a se alimentar do fruto proibido, gerando na humanidade a dualidade do bem e do mal. Importante frisar que diferente da visão cânon, em que o mal é resultado da ação humana, embora influenciado por Lúcifer, Satã ou qualquer denominação confessional pessoal que venha a interessar o leitor, o mal é instaurado pela ação humana no mundo, enquanto que no segundo caso (gnósticos) a humanidade é vítima dele. A dicotomia é importante para apresentar o conceito de caos primordial explicado por Ovídio ${ }^{8}$ em uma de suas poesias:

Antes do mar, da terra e do céu que tudo cobre, a natureza tinha, em todo orbe, um só rosto a que chamavam Caos, massa rude e indigesta; nada havia, a não ser o peso inerte e díspares sementes mal dispostas de coisa sem nexo. Inda nenhum Titã iluminava o mundo, nem Febe, no crescente, os chifres renovava, nem terra pendia no ar circunfuso, suspenso no seu peso, nem por longas margens, os seus braços haviam espraiado Anfitrite. E como ali houvesse terra, a onda inegável e o ar sem luz, a nada aderia uma forma, e cada coisa obstava outras, pois num corpo só o frio combatia o quente, o seco, o úmido, o mole o duro, e o peso o que não tinha peso (OVÍDIO, Metamorfósis, 5:20).

Para os gregos antigos, o caos foi a primeira entidade a surgir no cosmos, e o pouco que entendemos desse símbolo religioso é que ele é uma espécie de vazio separador, que se individualiza em um processo biológico parecido ao da mitose ${ }^{9}$, que dá origem a todas as outras coisas à partir da sua fragmentação. Essa primeira consciência cósmica, composta de uma natureza instável e divisível, permitiu o nascimento de consciências diferentes e plurais, seus primeiros filhos foram Nix (noite) e Érebo (escuridão). Sem me estender muito nessa discussão

8 Publio Ovídio Naso (20-43 d.C.), foi um poeta romano que é conhecido por obras como Metamorfósis, Heroides, Amores, e Ars Amatoria. Escreveu sobre amor, sedução, exílio e mitologia. Estudou retórica com grandes estudiosos de Roma.

9 É um processo de divisão celular, contínuo, onde uma célula dá origem a duas outras células. 
mitológica, parte da noção trágica da vida, amplamente discutida no teatro grego, tem inspiração na ideia de que o cosmos é uma criação de uma entidade que não tinha noção nenhuma para onde estava indo. Já no mito católico, o universo foi criado e organizado por uma consciência consciente de seu propósito.

Embora em muitos aspectos a teologia católica canônica e a gnóstica possam ser parecidas, lembre-se que o processo de criação entre essas duas visões teológicas é diametralmente oposto. Se por um lado temos uma criação organizada, perfeita e ordenada, do outro temos uma criação terceirizada, imperfeita e caótica. Para os gnósticos, o pecado e o mal do mundo são causados por um problema na estrutura da própria realidade e, portanto, não podem ser alterados. Dessa percepção surge a noção de terror cósmico, a noção de viver em um mundo, em que não importa o que você faça, no fim, não significará nada, onde não há redenção possível, pois não há pecado, o mal é parte estruturante da realidade material, e só reside no conhecimento da realidade aprisionadora do mundo material. Diante dessa realidade só nos resta o desespero.

\section{A origem do mal e gnosticismo invertido na obra: O Rei de Ama- relo de Robert W. Chambers.}

Robert W. Chambers foi um ilustrador e escritor de ficção estadunidense, que ficou conhecido em seu trabalho pelo livro intitulado " $O$ rei de amarelo". A obra é um trabalho de ficção e de terror publicado no formato de contos, algumas narrativas estão relacionadas entre si, outras não estão necessariamente interligadas. Se tratando de uma narrativa de terror, o mal é o tema principal das narrativas. Particularmente o terror, nunca foi uma narrativa atraente para mim, mas as fantasias sombrias, em especial, têm um modo bastante específico de lidar com o medo e o terror. Como apresentado no tópico que discute sobre os gnósticos e o caos primordial, o movimento religioso que ficou mais conhecido a partir do segundo século suspeitava que a realidade do universo fosse arquitetada de forma que não satisfizesse as necessidades humanas e tampouco estivesse preocupada com os interesses e preocupações dele. O terror proposto pela fantasia sombria é um terror psicológico, que surge a partir das expectativas e idealizações que a vida "consciente" constrói. No caso da espécie humana, temos uma programação mental 
que nos leva a acreditar que existe um sentido último por trás de uma ou outra experiencia de vida. Para lidar com o ressentimento o cérebro procura informações que sustentem uma narrativa consoladora que estimule o individuo a viver com a dor do trauma de um determinado sofrimento psicológico (BOYER, 2001).

Assim o verdadeiro terror, a maldição que pesa sobre a razão, é exatamente descobrir que o sentido do mundo, os planos, os desafios que supostamente encarei e derrotei, não são reais, apenas narrativas narcísicas sobre o próprio percurso individual da experiência pessoal. No caso do gênero da fantasia sombria, o mundo é arquitetado por criaturas sobrenaturais que estão no controle do mundo, os seres humanos são apenas peões dançando nas mãos dessas entidades, servindo-as nos bastidores e acreditando em contos de heróis e idealizações que lançam a vida humana no altar do sacrifício sobrenatural de maneira espontânea. No caso do livro que é o foco de análise desse artigo: " $O$ rei de amarelo", duas experiências são marcantes como momentos de inversão narrativa assustadora, o pavor do humano frente à descoberta dos poderes intransponíveis do sobrenatural. O primeiro caso pode ser encontrado no conto do reparador de reputações e está evidente nessa passagem:

Meu sangue subiu todo à cabeça, mas respondi apenas:

- É bom fazer uma limpeza completa.

- A ambição de Cézar e Napoleão empalidece diante desta que não pode descansar enquanto não tomar as mentes dos homens e controlar até os pensamentos que ainda não tiveram - disse o sr. Wilde.

- Está falando do rei amarelo - grunhiu com tremor.

- Ele é o rei a quem imperadores já serviram.

- Estou satisfeito em servir ele - retruquei (CHAMBERS, Robert, 2014, p.25).

Aqui, percebemos a passagem onde um personagem anuncia que toda a história humana foi construída a partir da vontade de uma entidade (rei amarelo) que manipula os corações dos homens nos bastidores da própria história. Esse elemento narrativo aproxima o terror de Robert com a filosofia gnóstica, que acreditava em uma realidade criada por um artesão que tenta controlar sua criação nos bastidores. Entretanto um elemento narrativo difere da filosofia gnóstica, afastando a fantasia 
sombria da narrativa gnóstica. Enquanto os gnósticos acreditavam que Jesus, um salvador celestial foi enviado para guiar o povo gnóstico para fora da caverna construída por Ialdabaõth, o gênero de terror sombrio discursa sobre a loucura, e como ela se instaura pela consciência racional de insuficiência, e a incapacidade frente a seu próprio destino. Dessa experiencia nasce o desespero que está em conhecer que a morte de um filho, de um relacionamento fracassado, ou a eterna corrupção de um modelo político, não é uma questão ética, e sim, consiste no aprisionamento da realidade humana manipulada por monstros que estão em guerra com outros monstros. Podemos concluir que a fantasia sombria absorve a narrativa do terror cósmico apresentado pelos gnósticos, mas inverte o protagonismo da razão como instrumento de libertação da realidade opressora. Diferente dos gnósticos que acreditavam que conhecimento (gnosis) liberta, para a fantasia sombria, o conhecimento dos elementos estruturantes da realidade leva a loucura. A descoberta de que o mundo é resultado do conflito de criaturas cósmicas que não se importam com a vida é o que leva o ser humano ao desespero. Portanto, temos uma inversão sutil de valor entre os gnósticos e a narrativa da fantasia sombria, visto que a razão é para um o caminho para a libertação, para o outro é a loucura. A recusa da razão apresentada pela fantasia sombria flerta com a ideia de que a felicidade e a ignorância estão intimamente relacionadas, e é preferível viver na ignorância e ser feliz do que buscar a decepção da verdade.

Outro tema recorrente nas narrativas de fantasia sombria é o tema da morte. No caso da obra escolhida como objeto de análise, o tema da morte é bastante sutil em muitos dos contos publicados no livro, mas num deles, o tema é o protagonista da narrativa. Eis abaixo um trecho que mostra essa preocupação com a morte:

E bem longe, após léguas de ondas nebulosas se quebrando, vi a lua derramando jatos d'água, e, além, as torres de Carcosa se erguiam atrás da lua. A morte e a morada horrível das almas perdidas, para onde minhas fraquezas havia muito o mandaram, tinham-no transformado aos olhos dos outros, mas não aos meus. E então ouvi sua voz, erguendo-se, mais encorpada trovejando pela luz radiante, e, enquanto eu caía, o brilho, aumentando cada vez mais, jorrou sobre mim em ondas e chamas. Então, mergulhei nas profundezas e ouvi o Rei amarelo sussurrando para minha alma: "Horrenda coisa é cair nas mãos do Deus vivo!" (CHAMBERS, Robert, 2014, p.61). 
Como descrito acima, essa passagem conta a estória de um senhor que seguindo sua rotina diária, e diante do tédio dessa rotina, adormece durante um sermão em uma igreja. Durante o sono, encara seus medos pessoais, até perceber que na verdade havia morrido, e diante da morte nada podia fazer. O tema da morte é uma narrativa poderosa para discutir o quão pequena é a espécie humana diante do tamanho da criação, e que diante dela, nada pode.

Por fim concluímos que a fantasia sombria, se não inspirada pelas bases teológicas e filosóficas do pensamento gnóstico, no mínimo me permite afirmar que existe uma intertextualidade entre ambas as narrativas, salvas as diferenças particulares que cabem para o movimento religioso e o gênero literário.

\section{Fantasia sombria, ficção e cultura popular}

\subsection{Fantasia sombria e o crepúsculo da razão ${ }^{10}$}

Georges Bataille ${ }^{11}$, que ficou conhecido na filosofia por sua proximidade com o pensamento de Nietzsche, pensava que a engrenagem fundamental que movimenta uma narrativa dentro de uma obra literária é o tema do mal (JORON, 2013). Embora para a literatura em geral, essa afirmação seja um pouco exagerada, no caso da fantasia sombria, ela com certeza se torna possível. No caso do livro $O$ rei de amarelo, o tema da origem do mal, e da participação da espécie humana no combate do mal é recorrente em quase todas as obras onde a narrativa é desenvolvida a partir da perspectiva da fantasia sombria. Há influência direta sobre Robert Chambers do conto de Ambrose Bierce intitulado: "Um habitante de Carcosa", que questiona os limites entre a racionalidade e a loucura, na mesma linha narrativa de alguns contos do rei de amarelo. Podemos afirmar, portanto, que a crítica da razão parece ser um tema recorrente na fantasia sombria. O chamado de cthulhu e

10 Crepúsculo é um fenômeno natural que ocorre todos os dias, ao sol nascer e se por. O uso do conceito nesse texto é usado como uma metáfora para referenciar o caráter ambíguo instável da razão que é um dos temas principais abordados por este artigo.

11 Georges Bataille (1897-1962) foi um escritor francês, cuja obra se enquadra tanto no domínio da literatura como no campo da Antropologia, Filosofia e Arte. A transgressão do sagrado, o sagrado e o erotismo são temas abordados em seus escritos. Também ficou conhecido pelo desenvolvimento do método heurístico na filosofia. 
outros contos de H.P. Lovecraft ${ }^{12}$ são bons exemplos, que remontam a uma genealogia narrativa que vai de Mary Shelley, Ambrose Pierce até Robert Chambers. Dentro desse gênero narrativo, a razão não é instrumento de salvação e sim de condenação, há dúvidas e medo em relação ao potencial humano através das conquistas tecnológicas e científicas, como no caso do doutor Frankenstein que, ressentido pela dor da morte da sua mãe, desenvolve um método cientifico para trazer pessoas de volta do reino dos mortos, que, em última análise, fracassa. A criatura, produto da razão e da engenhosidade humana, desperta apenas para destruir a vida e a felicidade do arrogante doutor que pensava conquistar o domínio dos deuses (SHELLEY, 2017). Dessa genealogia narrativa, o que separa Mary Shelley dos outros autores é o formato da publicação, e os deuses que manipulam a humanidade de seus bastidores ancestrais, como Hastur (outro nome para descrever o rei de amarelo) de Ambrose Bierce e o rei de amarelo de Robert Chambers. Mas foi em Lovecraft que esse gênero narrativo ganhou toda uma mitologia própria, nomeada de mitos de Cthulhu.

De maneira geral, tanto em Mary Shelley, quanto em Bierce, Chambers e Lovecraft, a razão é tema de suspeita e desconfiança frente à sua capacidade de potencializar a capacidade humana de interferir na ordem natural do universo. Acredito que Mary Shelley não entre especificamente no gênero fantasia sombria, porque a desconfiança de Mary em relação à razão é tão grande que seu livro sugere que a razão é quase como a origem do mal da humanidade, e esse aspecto aproxima Mary da narrativa católica do pecado original da mitológica cristã canônica. O próprio subtítulo de Frankenstein: "o prometeu moderno", é uma referencia ao mito grego com uma mensagem narrativa na mesma linha teológica do mito do paraíso perdido cristão. Já no caso da fantasia sombria, a descoberta da "verdade" das estruturas que movimentam a realidade humana leva a loucura. A crítica por trás da "loucura" da razão da fantasia sombria reside no terror da descoberta, pois o saber das coisas isola, individualiza, e aqui está claro que o processo de individualização leva ao delírio e ao afastamento da "realidade" cotidiana. Na discussão estabelecida pelo gênero sombrio há

12 Howard Phillips Lovecraft (1890-1937), escritor e revolucionário do gênero do terror, atribuindo-lhe elementos fantásticos típicos de gêneros de fantasia e ficção cientifica. 
uma inversão clara no valor do princípio Aristotélico, da associação da virtude ao pensamento racional: "julga-se que seja característico de um homem dotado de sabedoria, ser capaz de deliberar acerca do que é bom e conveniente para ele, não sob um aspecto particular" (Aristóteles, EN, VI, 1140a27). Não dá para entender, pelo menos do meu ponto de vista, se os autores que adotam esse gênero narrativo tomam o partido da racionalidade delirante e sobrenatural ou da prisão da felicidade e do bem estar social.

\subsection{Fantasia sombria e cultura popular}

Mesmo o gênero sombrio sendo bem mais antigo que seu autor mais conhecido, Lovecraft, é a partir dele que o gênero se capilariza em diferentes mídias. Sua influência é tamanha, que muitas das produções de fantasia, hoje, de uma forma direta ou indireta, fazem referência ao gênero. A série da HBO True Detective (verdadeiro detetive), constrói seu roteiro, inteiramente baseado no livro: o rei de amarelo, muitas vezes trazendo para a trama passagens de alguns contos. O clássico The $X$-files (arquivo x), é outro exemplo, onde paranoia, conspiração e seres extraterrestres desafiam os limites daquilo que Fox Mulder e Dana Scully acreditam conhecer. Na Netflix, temos o famoso Stranger Things (coisas estranhas) que apresenta Nyarlathotep, o mensageiro dos deuses, personagem inspirado a partir das referências dos mitos de Lovecraft, que conecta as dimensões material e espiritual, como principal vilão da série, E temos também a série mais aclamada da história: Game of Trones (guerra dos tronos), que faz referências à fantasia do rei de amarelo, ao mencionar um feiticeiro, que no passado foi um antigo rei amarelo do grande império dourado de Yi-Ti, como rei e habitante de Carcosa, em uma cidade esquecida e inacessível para além das terras sombrias de Asshai.

A influência não se estende somente aos filmes e séries de TV. As histórias em quadrinhos (HQ's) também fazem referências sutis ao gênero: a minissérie Crepúsculo esmeralda (revista da lanterna verde), conta a história de Hal Jordan, ex-lanterna verde, em uma jornada que o transforma em uma criatura cósmica, reinando absoluto como demiurgo do real em seus trajes e poderes cósmicos amarelos. Há também o 
gênero musical "Hard Rock ${ }^{13}$ " que se inspirou nos mitos de Cthulhu para criar algumas das letras de suas canções. Exemplos reconhecidos são as bandas Black Sabbath e Metallica, que fazem uma referência com a letra da música ao Chamado de Cthulhu.

Assim sendo, podemos concluir, a fantasia sombria é matéria prima, pelo menos nos Estados Unidos, e fonte imagética e arquetípica de personagens, modelos e histórias que estruturam muitas das estórias de fantasia produzidas no universo auto-intulado geek $k^{14}$.

\section{Considerações finais}

Neste artigo tentamos apontar algumas evidências que sustentam nossa hipótese inicial de que o gênero "fantasia sombria" e, mais especificamente, o livro o rei de amarelo de Robert Chambers, estabelecem uma intertextualidade com a teologia gnóstica, invertendo o papel da razão e do conhecimento como protagonista da libertação humana das garras do destino cósmico. Como bem explicado por Nietzsche:

No desvio de algum rincão do universo inundado pelo fogo de inumeráveis sistemas solares, houve uma vez um planeta no qual animais inteligentes inventaram o conhecimento. Este foi o minuto mais soberbo e mais mentiroso da "história universal", mais foi apenas um minuto. Depois de alguns suspiros da natureza, o planeta congelou-se e os animais inteligentes tiveram de morrer. (NIETZSCHE, Friedrich, 2001, p. 7).

Tentamos mostrar a suspeita de que o gênero estabelece os limites da racionalidade humana poder conhecer a realidade à sua volta, muitas vezes entendendo que a racionalidade é um caminho para a loucura, desespero e morte. Assim como a visão cética de Nietzsche, a fantasia sombria entende que o conhecimento é apenas mais uma ilusão criada para lidar com o ressentimento humano que, diante do cosmo, nada representa e nada pode fazer. O ser humano não evolui moralmente, o conhecimento não nos leva a evitar os erros do passado,

13 Hard Rock é um estilo musical, subgênero do rock que tem suas raízes no rock de garagem e psicodélico do meio da década de 1960, que se caracteriza por ser consideravelmente mais pesado do que a música rock tradicional.

14 Termo que se refere a uma cultura de pessoas que são aficionadas em tecnologia, livros, videogames, filmes e cultura pop em geral. 
o conhecimento é apenas um delírio sobre o homem se tornar o centro do universo.

Para além da tentativa de mostrar os fundamentos de uma interpretação pessoal, esse artigo tenta apontar as influências que o gênero "sombrio" tem nas obras de fantasia estadunidenses, a relevância que o gênero exerce dentro do imaginário popular estadunidense e geek. Por fim, o artigo também me levou a considerar uma possível observação a respeito do fenômeno religioso: religiões em que os mitos da criação envolvem o caos primordial, e em que as entidades cósmicas e a vida se capilarizam a partir da individuação da substancia divina, desenvolvem um sistema moral menos rígido, pois veem o humano como vitima da vontade cósmica. Já sistemas que surgiram a partir de mitos de criação ordenados, racionais, como o design inteligente, me parecem mais fechados em si mesmos, menos dispostos à pluralidade, pois existe neles uma disputa moral. Me parece que essas religiões precisam preencher o papel de limitador cósmico que as entidades "malignas" de Lovecraft, ou o Ialdabaõth gnóstico exercem em suas respectivas mitologias.

\section{Bibliografia}

ARISTÓTELES. Ética a Nicômaco. São Paulo: Martin clarete, 2003.

BOYER, Pascal. Religion explained: the evolutionary origins of religious thought. New York: Basic books, 2001.

CHAMBERS, Richard W. O Rei de amarelo. Rio de Janeiro: Intrínseca, 2014. DESCARTES, René. Meditações metafisicas. São Paulo: Martins fontes, 2011. FRYE, Northrop. A anatomia da crítica: quatro ensaios. São Paulo: Editora Realizações, 2014.

GUTIÉRREZ, Jorge Luiz. Literatura e religião: o conceito de caos no mundo antigo. In: Ciências da religião: história e sociedade, São Paulo, v.14, n.2, p.45-63, jun./dez.2016.

JORON, Philippe. A soberania do mal: Georges Bataille e a inocência culpada da literatura. In: Intercom - RBCC. São Paulo, v.36, n.1, p. 271-287, jan.jun.2013.

LAYTON, Bentley. As escrituras gnósticas. São Paulo: edições Loyola, 2002.

LOVECRAFT, Howard P. O chamado de Cthulhu e outros contos. São Paulo: L\&M pocket, 2017. 
A origem do mal e o crepúsculo da razão na obra do rei de amarelo de Robert W. 187 Chambers: teologia e literatura na cultura popular contemporânea.

NIETZSCHE, Friedrich. Verdade e mentira no sentido extramoral. In: Comum - Rio de Janeiro - v.6. - n.17 - p.05-23 - jul./dez. 2001).

OVÍDIO. Metamorfósis. São Paulo: Hedra, 2006.

SHELLEY, Mary. Frankenstein ou o Prometeu moderno. Ed. de luxo. Rio de Janeiro: Zahar, 2017. 